\title{
Fetus papyraceous: a case report of preterm premature rupture of membranes with adherent placenta
}

\author{
Dr. N.V. Manjula, M.B.B.S., M.S., ${ }^{1}$ Dr. B. K. Sujani, M.B.B.S., M.S., ${ }^{1}$ Dr. Shakila \\ Shetty, M.B.B.S., D.G.O., M.S. ${ }^{1}$
}

\begin{abstract}
Key Words: Adherent placenta, fetus papyraceous, multiple pregnancy, fetal death, placenta, obstetric labor complications, diseases in twins, labor stage, third
\end{abstract}

\begin{abstract}
Fetus papyraceous is a rare condition and is associated with obstetric complications. Antenatal diagnosis of this condition aids in follow-up care of co twin(s) as well as to predict future obstetric complications. In this report, we describe a case of fetus papyraceous identified after the manual removal of adherent placenta.

1 Department of Obstetrics and Gynecology, M.S. Ramaiah Medical College, Bangalore, Karnataka, India.
\end{abstract}

\section{Introduction}

Fetus papryceous [FP] is a rare and uncommon event with a report incidence of 1 in 12,500. ${ }^{1}$ Here we report a case of FP with preterm premature rupture of membranes with adherent placenta.

\section{Case Report}

A 22 year old primigravida was admitted to the labor ward on 08-242011 at 10:30 PM. The subject was estimated at 29 weeks of gestation and presented in second stage of labor with a breeched fetus with preterm premature rupture of membranes of 24 hours and labor pains for 6 hours. The conception was spontaneous and prior menstrual cycles were regular.

The subject had received regular antenatal care in a private hospital and had one ultrasound examination at the fifth month of gestation that showed a single live intra uterine fetus with an estimated gestation of 20 weeks and no anomalies. Routine examinations and the coagulation profile were within normal limits.

The subject delivered a live preterm female baby by breech presentation. The baby weighed $1000 \mathrm{gms}$ with an APGAR score of 4 at 1 and 6 at 5 mins. The baby cried immediately after birth and was transferred to Neonatal Intensive Care Unit for preterm management. After delivery the subject's vitals were normal.

However there were no signs of spontaneous expulsion of placenta or indications of placental expulsion for more than 1 hour post-delivery. Thus

Please cite this paper as: Manjula NV, Sujani BK, Shetty S. Fetus papyraceous: a case report of preterm premature rupture of membranes with adherent placenta. Proc Obstet Gynecol. 2011 November;2(2):Article 16 [ 4 p.]. Available from: http://ir.uiowa.edu/pog/. Free full text article.

Corresponding author: Dr. N.V. Manjula, No. $11,1^{\text {st }}$ Cross, Judicial Layout, R.M.V. $2^{\text {nd }}$ Stage, Sanjay Nagar, Bangalore - 560094, Karnataka, India. manjulanv kv@yahoo.co.in 
the patient was transferred to the operation theatre and manual removal of placenta was performed under short general anaesthesia (propofol). After the expulsion of placenta and membranes, FP that was adherent to the placenta was noted (Figure 1). The FP weighed around $100 \mathrm{gms}$ and measured $8 \mathrm{cms}$ in length. The placenta weighed $150 \mathrm{gms}$. The mother and baby were discharged on third postnatal day against the advice of the obstetrician and pediatrician. No follow-up was available for the patient or baby as they were lost for follow up.

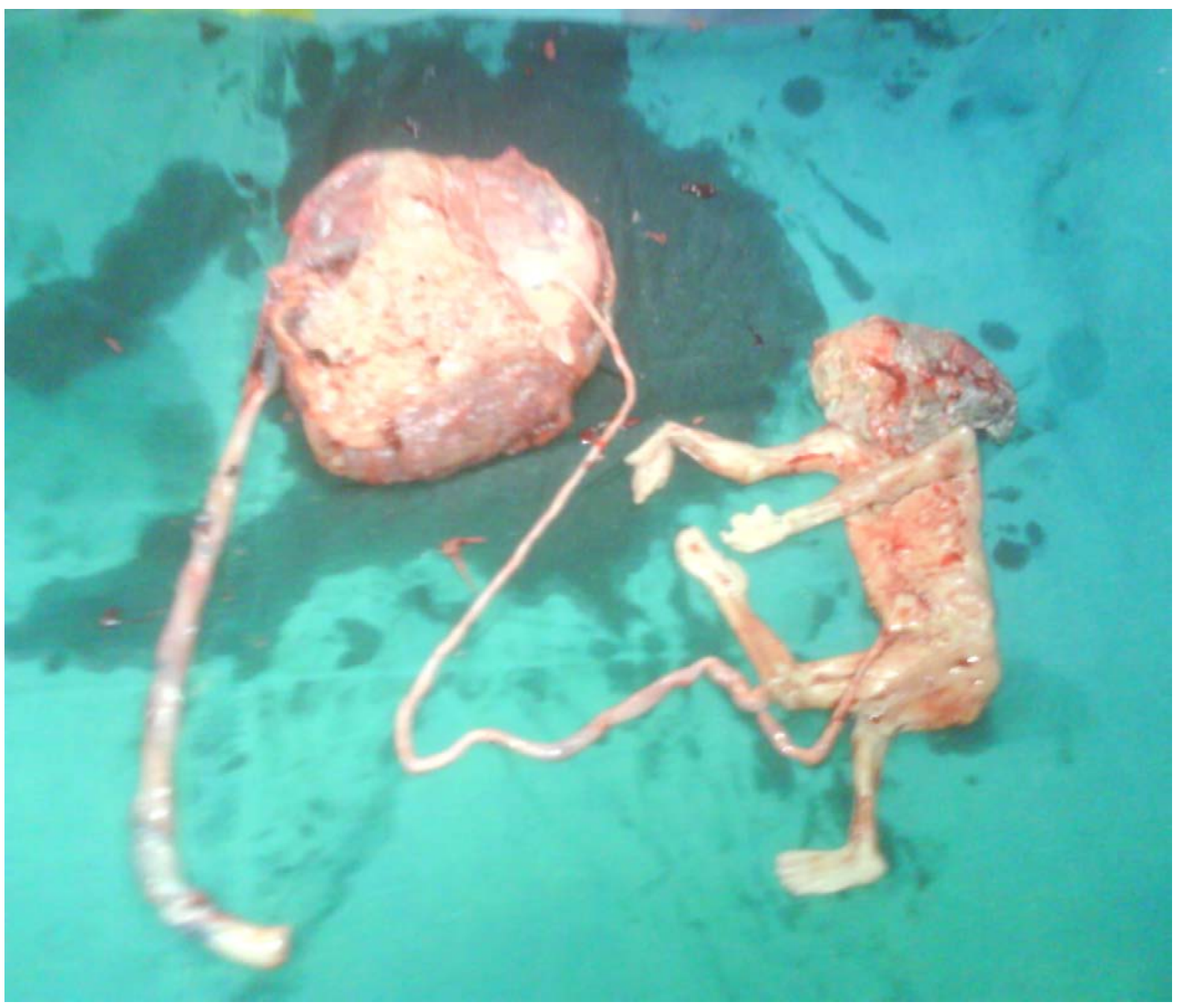

Figure 1 Legend: Placenta and membrane with attenuated umbilical cord with fetus papyraceous and normal umbilical cord.

\section{Discussion}

FP is a rare condition and is seen in 1 in 12,500 cases. FP occurs in subjects with multiple gestation and is characterized by the death of one or more fetuses early in the gestation period (i.e. at 15 to 20 weeks), whereas the other fetuses continue to grow. In most situations the fluid of the dead tissue is gradually absorbed, the amniotic fluid disappears, and the 
fetus is compressed and becomes incorporated into the membranes. ${ }^{2}$

A previous report documented intrauterine death of one twin at late gestational age (second trimester), which was diagnosed antenatally during an ultrasound; however, a healthy fetus was delivered at gestational term and an FP expelled. 7,8 When undiagnosed antenatally, FP has the potential to obstruct labor and can thus only be diagnosed postdelivery. ${ }^{9,10}$ Extending previous observations in this case report, we describe how FP also obstructs placental expulsion.

Spontaneous reduction of one or more gestational sacs before the twelfth week of gestation in $36 \%$ of twins, $53 \%$ of triplets, and $65 \%$ of quadruplets has been reported. ${ }^{3}$ After 20 weeks of gestation, the incidence of death of one fetus is $2.6 \%$ in cases of twins and $4.3 \%$ in triplets. Increased risk of fetal death is associated with monochorionic placenta, disproportionate sharing of placenta, and monozygosity. ${ }^{4}$ In multiple pregnancies, the intrauterine death of one twin is associated with serious mortality and morbidity of the surviving twin; for example multicystic encephalomalacia occurs in $20 \%$ of surviving co twins as a result of severe fetal hypotension and hypoxia, ${ }^{5}$ which contributes to the increased morbidity of the surviving twin. Furthermore, the risk of serious cerebral impairment in the surviving twin following fetal death is about 1 in $5,{ }^{6}$ and twin embolization syndrome complicates $25 \%$ of cases with a surviving twin. ${ }^{7}$ The emboli can predominantly damage highly vascularized organs such as the brain and kidneys but can also affect all organs systems, causing central nervous system abnormalities like encephalomalacia and extra cranial abnormalities such as small bowel atresia, gastroschisis, hydrothorax, renal cortical necrosis, and aplasia cutis. $^{7}$

\section{Conclusions}

In cases of undiagnosed FP, retained placenta, obstructed labor and obstruction to placental delivery can occur. A careful exploration of the placenta and membranes should be performed as many FP are diagnosed after delivery.

\section{REFRENCES:}

1. Rathi BA, Rathi SM. Fetaus papyraceous - a case report. J Obstet Gynaecol India 2003;53:188.

2. Mittal PS, Khanna M. Two papyraceous fetuses in a triplet pregnancy. J Obstet Gynecol India 2007Jan/Feb;57(1):77-78

3. Dickey RP, Taylor SN, Lu PY, Sartor BM, Storment JM, Rye PH, Pelletier WD, Zender JL, Matulich EM. Spontaneous reduction of multiple pregnancy: incidence and effect on outcome. Am J Obstet Gynecol. 2002 Jan;186(1):77-83.

4. Johnson CD, Zhang J. Survival of other fetuses after a fetal death in twin or triplet pregnancies. Obstet Gynecol. 2002 May;99(5 Pt 1):698-703. 
5. Weiss JL, Cleary-Goldman J, Tanji K, Budorick N, D'alton ME. Multicystic encephalomalacia after first-trimester intrauterine fetal death in monochorionic twins. Am J Obstet Gynecol. 2004 Feb;190(2):563-5.

6. Pharoah PO, Adi Y. Consequences of in-utero death in a twin pregnancy. Lancet. 2000 May 6;355(9215):1597602.

7. Upadhyaya I, Pradhan M, Sharma R. Twin pregnancy with fetus papyraceous. JNMA J Nepal Med Assoc. 2009 Jul-Sep;48(175):246-8.
8. Sutkin G, Mamlok V. Images in clinical medicine. Fetus papyraceus. $\mathrm{N}$ Engl J Med. 2004 Apr 15;350(16):1665.

9. Koregol MC, Nayak R, Kandasamy $\mathrm{S}$, Bhandary A, Mahale N, Dodawad A. Fetus papyraceous: a rare cause for obstruction to spontaneous placental expulsion. Arch Gynecol Obstet. 2009 Jun;279(6):945-7. Epub 2009 Jan 17.

10. Lau WC, Rogers MS. Fetus papyraceous: an unusual cause of obstructed labour. Eur J Obstet Gynecol Reprod Biol. 1999 Sep;86(1):109-11. 